\title{
Pin1 regulates TGF- $\beta 1$ production by activated human and murine eosinophils and contributes to allergic lung fibrosis
}

\author{
Zhong-Jian Shen, ${ }^{1,2}$ Stephane Esnault, ${ }^{1,2}$ Louis A. Rosenthal, ${ }^{3}$ Renee J. Szakaly, ${ }^{3}$ \\ Ronald L. Sorkness, ${ }^{4}$ Pamela R. Westmark, ${ }^{1,2}$ Matyas Sandor, ${ }^{2}$ and James S. Malter ${ }^{1,2}$ \\ ${ }^{1}$ Waisman Center for Developmental Disabilities, ${ }^{2}$ Department of Pathology and Laboratory Medicine, and ${ }^{3}$ Department of Medicine, University of Wisconsin \\ School of Medicine and Public Health, Madison, Wisconsin, USA. ${ }^{4}$ Department of Medicine and Pediatrics and School of Pharmacy, \\ University of Wisconsin, Madison, Wisconsin, USA.
}

\begin{abstract}
Eosinophilic inflammation is a cornerstone of chronic asthma that often culminates in subepithelial fibrosis with variable airway obstruction. Pulmonary eosinophils (Eos) are a predominant source of TGF- $\beta 1$, which drives fibroblast proliferation and extracellular matrix deposition. We investigated the regulation of TGF- $\beta 1$ and show here that the peptidyl-prolyl isomerase (PPIase) Pin1 promoted the stability of TGF- $\beta 1$ mRNA in human Eos. In addition, Pin1 regulated cytokine production by both in vitro and in vivo activated human Eos. We found that Pin1 interacted with both PKC- $\alpha$ and protein phosphatase 2A, which together control Pin1 isomerase activity. Pharmacologic blockade of Pin1 in a rat asthma model selectively reduced eosinophilic pulmonary inflammation, TGF- $\beta 1$ and collagen expression, and airway remodeling. Furthermore, chronically challenged $\mathrm{Pin}^{-/-}$mice showed reduced peribronchiolar collagen deposition compared with wild-type controls. These data suggest that pharmacologic suppression of Pin1 may be a novel therapeutic option to prevent airway fibrosis in individuals with chronic asthma.
\end{abstract}

\section{Introduction}

Persistent asthma is characterized by chronic pulmonary inflammation, which often culminates in airway fibrosis. The development of airway disease is referred to as remodeling and includes the deposition of subepithelial collagen (types I, III, and V), fibroblast proliferation, and smooth muscle hypertrophy (1). While macrophages, $\mathrm{T}$ cells, mast cells, and neutrophils as well as resident smooth muscle cells and fibroblasts release profibrotic cytokines, the degree of eosinophilic inflammation in asthmatic airways shows the greatest correlation with progressive fibrosis and remodeling (2). Reductions in pulmonary eosinophilia after anti-IL-5 treatment (3) or genetic ablation in mice (4) significantly decreased the content of airway ECM induced by allergen challenge, confirming the pivotal role of eosinophils (Eos) in this pathologic process.

Eos-derived TGF- $\beta 1$ is a critical determinant of pulmonary immunity and fibrosis (5), functioning as a potent chemoattractant for monocytes (6) and fibroblasts (7), as well as a modulator of Treg functions (8). Anti-TGF- $\beta 1$ treatment reduced pulmonary inflammation and attenuated airway remodeling following allergen challenge (9), while intrapulmonary administration or expression of recombinant TGF- $\beta 1$ induced substantial matrix deposition and fibrosis $(10,11)$. Taken together, these animal and human studies strongly suggest that the influx and persistence of activated Eos producing TGF- $\beta 1$ drive both short- and long-term airway fibrosis

Nonstandard abbreviations used: ARE, AU-rich element; AREBP, ARE-binding protein; AUF1, ARE-binding factor 1; BAL, bronchoalveolar lavage; Eos, eosinophil(s); $\mathrm{HA}$, hyaluronic acid; HuR, Hu antigen R; PP2A, protein phosphatase 2A; PPIase, peptidyl-prolyl isomerase; qPCR, real-time quantitative PCR; RAG, ragweed pollen extract; TIA-1, T cell intracellular antigen 1; TTP, tristetraprolin; UTR, untranslated region; YB-1, Y-box binding protein 1.

Conflict of interest: The authors have declared that no conflict of interest exists. Citation for this article: J. Clin. Invest. 118:479-490 (2008). doi:10.1172/JCI32789. and facilitate ongoing inflammation. Despite its importance, the molecular mechanisms underlying TGF- $\beta 1$ expression by activated Eos remain unknown.

TGF- $\beta 1$ expression is regulated at multiple levels, including transcription, mRNA stability, and posttranslational processing (12). The expression of TGF- $\beta 1$ by Eos is sensitive to cytokines (IL-3, -4 , and -5) (13) or other physiologic agonists such as hyaluronic acid (HA) (14). TGF- $\beta 1$ mRNA can be rapidly ( $2-6$ hours) induced by stimulation of mesangial cells (15) and T lymphocytes (16) through intracellular signaling kinases including PKC or ERK. These kinases are also involved in the stability of many proinflammatory cytokine mRNAs that contain AU-rich 3' untranslated regions (UTRs) (17) and, less frequently, coding region determinants (18). Recent data suggest that occupancy of the AU-rich elements (AREs) by functionally distinct RNA-binding proteins (tristetraprolin [TTP], Hu antigen R [HuR], ARE-binding factor 1 [AUF1], and Y-box binding protein 1 [YB-1]) underlies differential decay (17).

Recently, we have identified Pin1, a peptidyl-prolyl isomerase (PPIase), as a key regulator of inflammatory cytokine expression by activated Eos and T cells $(19,20)$. Pin 1 bound to and modulated the affinity of AUF1 for GM-CSF mRNA in response to external stimuli, leading to changes in GM-CSF mRNA decay, accumulation, and translation. Pin 1 is the only mammalian enzyme known to specifically catalyze the cis-trans isomerization of Ser-Pro or Thr-Pro peptide bonds. Pin 1 contains an N-terminal WW domain, which binds to Ser/Thr-Pro-containing proteins, and a C-terminal PPIase domain. To date, Pin 1 has been linked to cell-cycle control, apoptosis, neurodegeneration, and tumorigenesis (21).

Here we demonstrate that Pin 1 regulates the decay, accumulation, and translation of TGF- $\beta 1$ mRNA in Eos activated both in vitro and in vivo. Pin 1 controls the association of a subset of ARE-binding proteins (AREBPs) with TGF- $\beta 1$ mRNA and with the mRNA decay machinery. Pin 1 associated with and was regulated 

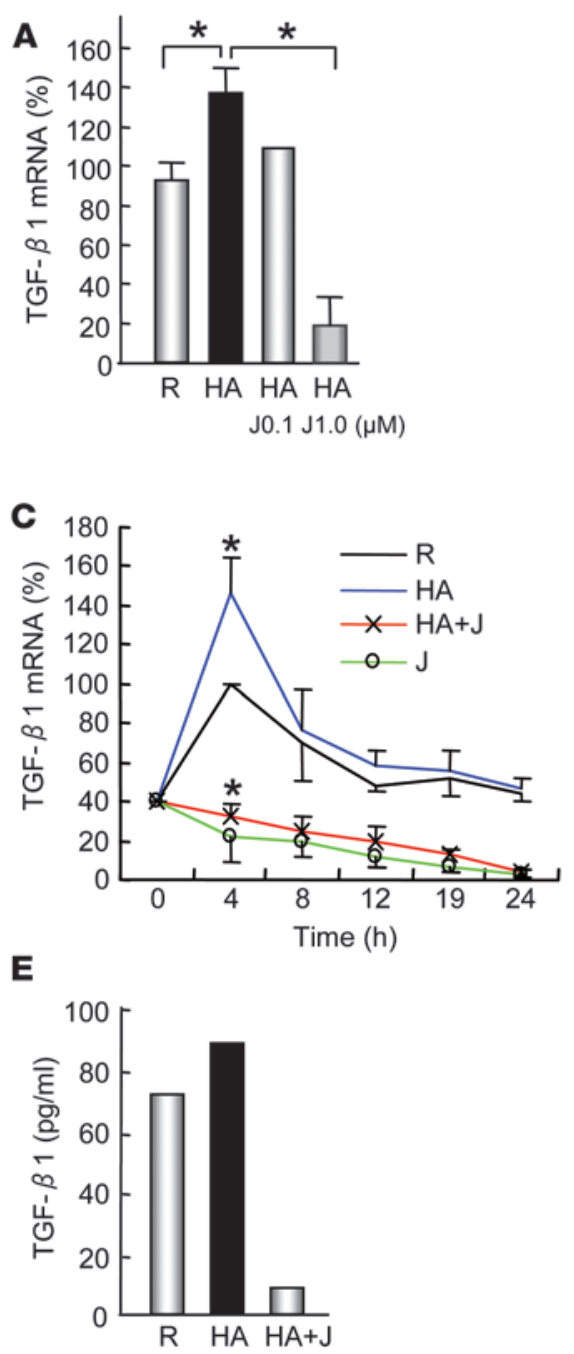

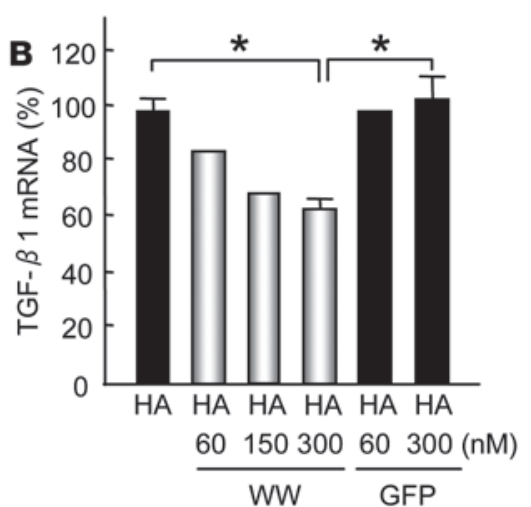

D

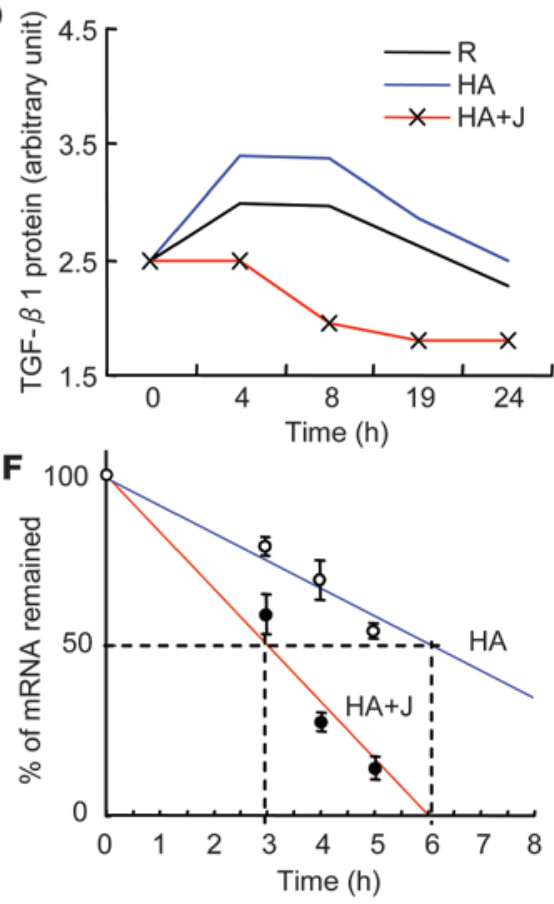

Figure 1

Pin 1 is required for TGF- $\beta 1$ mRNA expression. (A, B, C, and E) Reverse transcription and qPCR (RT-qPCR) analysis for TGF- $\beta 1$ mRNA. (A) Eos left untreated (resting $[\mathrm{R}]$ ) or incubated for 4 hours with HA alone (100 $\mu \mathrm{g} / \mathrm{ml}$ in all experiments) or with juglone (0.1 or $1.0 \mu \mathrm{M}$ ) prior to analysis. (B) Cells incubated for 4 hours with $\mathrm{HA}$ alone, with $60-300$ nM TAT-WW-Pin1 (WW) or TAT-GFP (GFP) prior to analysis. (C) Cells left untreated or incubated for the indicated times with $\mathrm{HA}$ alone or with juglone $(1.0 \mu \mathrm{M})(\mathrm{HA}+\mathrm{J})$ or juglone alone (J) before collection and analysis at the times shown. (D) Intracellular levels of TGF- $\beta 1$ protein were measured by immunoblotting of total cell lysates under reducing conditions and signal quantitated by densitometry and normalized to $\beta$-actin. (E) ELISA for TGF- $\beta 1$ protein. Cells left untreated or incubated for 24 hours with HA alone or with juglone before collection of culture medium. The data are mean of 2 independent experiments. (F) Decay of TGF- $\beta 1$ mRNA. Cells were treated for 2 hours with HA alone or with juglone, followed by the addition of $50 \mu \mathrm{g} / \mathrm{ml}$ of DRB (5,6-dichloro-1- $\beta$-D-ribofuranosylbenzimidazole) to block transcription. Cells were then collected at the times shown for analysis. Error bars indicate mean \pm SD of 3 independent experiments with different donors. ${ }^{*} P<0.05$ by Student's $t$ test in a 2-tailed analysis. by PKC- $\alpha$ and protein phosphatase 2A (PP2A). In vivo inhibition of Pin 1 selectively and significantly reduced eosinophilic inflammation, TGF- $\beta 1$ and collagen mRNA, and protein in bronchoalveolar lavage (BAL) fluid, airways, and total lung of allergen-sensitized and -challenged rats. Similarly, reduced airway collagen deposition was also observed in Pin1-knockout mice after chronic allergen challenge. These data suggest that Pin 1 may be a therapeutic target to prevent airway remodeling in individuals with chronic asthma.

\section{Results}

Pin 1 activity is required for TGF- $\beta 1 \mathrm{mRNA}$ expression by peripheral blood Eos. Suppression of lung eosinophilia by anti-IL-5 therapy in humans (3) or genetic ablation in mice (4) reduced airway fibrosis and pulmonary TGF- $\beta 1$ content. These data suggest that Eos are a major source of TGF- $\beta 1$ during remodeling. Pin 1 regulated GMCSF production in Eos at a posttranscriptional level by modulating the function of the AREBPs HuR and AUF1 (19), which have been implicated in profibrotic cytokine mRNA regulation as well (22, $23)$. Therefore, we evaluated whether Pin 1 plays a role in TGF- $\beta 1$ expression by activated Eos. Real-time quantitative PCR (qPCR) analysis revealed constitutively high levels (threshold cycle 18-23; data not shown) of TGF- $\beta 1$ mRNA in freshly isolated peripheral blood Eos from normal or mildly atopic donors. Activation with $\mathrm{HA}$, an ECM proteoglycan that is elevated in the lung of asthmatic individuals, consistently increased TGF- $\beta 1$ mRNA (40\%-50\%) (Figure 1A), an effect that was suppressed by juglone, a selective Pin1 inhibitor (24) (Table 1), without affecting housekeeping S26 mRNA. Low-dose juglone $(0.2-1.0 \mu \mathrm{M})$ for 24 hours had no effect on cell viability (19). IL-3, -4 , and -5 and GM-CSF, which are all elevated in the lung of asthmatic individuals and modestly enhanced TGF- $\beta 1$ secretion by Eos (13), had no effect on TGF- $\beta 1$ mRNA content (data not shown). These data are consistent with microarray analysis of IL-5 - or GM-CSF-stimulated Eos (25), suggesting that HA signaling, through CD44 (26), controls TGF- $\beta 1$ expression by these cells.

In order to further confirm the role of Pin 1 in the regulation of TGF- $\beta 1$, Eos were transduced with the WW domain of Pin 1 fused at the $\mathrm{N}$ terminus to a TAT penetratin tag (TAT-WW-Pin1) (27). The WW domain functions as a dominant negative by preventing endogenous Pin 1 from binding to Ser/Thr-Pro targets (21). TAT-WW-Pin 1 significantly reduced HA-mediated TGF- $\beta 1$ mRNA upregulation in a dose-dependent fashion $(60-300 \mathrm{nM})$ 


\section{Table 1}

The effects of Pin1, PKC, and PP2A activators and inhibitors on TGF- $\beta 1$ mRNA expression in human Eos

\begin{tabular}{|c|c|c|c|c|}
\hline Agent & Major action & Dose used & $\begin{array}{c}\text { Effect on } \\
\text { TGF- } \beta 1 \text { mRNA }\end{array}$ & $\begin{array}{l}\text { Cell viability } \\
\text { (after } 3 \text { d) }\end{array}$ \\
\hline $\mathrm{HA}$ & Pin1 activator & $100 \mu \mathrm{g} / \mathrm{ml}$ & Stabilize, increase & Increase \\
\hline Juglone & Covalent Pin1 inhibitor & $0.1-1 \mu \mathrm{M}$ & Destabilize, decrease & Reduce \\
\hline TAT-WW-Pin1 & Competitive Pin1 inhibitor & $150-300 \mathrm{nM}$ & Decrease & Reduce \\
\hline Gö6976 & PKC- $\alpha / \beta 1$ inhibitor & $10-50 \mathrm{nM}$ & Decrease & Reduce \\
\hline Safingol & PKC- $\alpha / \beta 1$ inhibitor & $5-25 \mathrm{nM}$ & Decrease & Reduce \\
\hline 12(S)-HETE & PKC- $\alpha$ agonist & $5-20 \mathrm{nM}$ & Increase & Increase \\
\hline Thymeleatoxin & PKC- $\alpha$ agonist & $5-20 \mathrm{nM}$ & Increase & Reduce \\
\hline Okadaic acid & PP2A inhibitor & $5-50 \mathrm{nM}$ & Decrease & Reduce \\
\hline PD98059 & MEK1 inhibitor & $50 \mu \mathrm{M}$ & Moderately decrease & Reduce \\
\hline
\end{tabular}

Summary of the actions of activators and inhibitors for Pin1, PKC- $\alpha$, and PP2A on Pin1 isomerase activity, TGF- $\beta 1$ mRNA level, and protein secretion and Eos survival.

the inhibitor studies, specific PKC- $\alpha$ agonists 12 (S)-HETE (32) and thymeleatoxin (TXA) (Table 1) (33) significantly upregulated TGF- $\beta 1$ mRNA, which was antagonized by Gö6976 (Figure 2C). Therefore, PKC- $\alpha$ but not ERK signaling is required for TGF- $\beta 1$ upregulation by $\mathrm{HA}$ activated Eos.

PP2A and PKC- $\alpha$ interact with and regulate Pin1. As both Pin 1 and PKC- $\alpha$ blockade reduced TGF- $\beta 1$ mRNA levels and Pin 1 activity is modulated by phosphorylation, we asked whether PKC- $\alpha$ and Pin 1 interacted. PKC- $\alpha$ contains 4 potential Pin1-binding sites, including Thr638-Pro639, which is often phosphorylated after cell activation both in vitro and in vivo (34, 35). Pin 1 is known to regulate a vari-

(Figure 1B), whereas recombinant TAT-GFP had no effect. Kinetic analysis showed that HA induced maximal increases in TGF- $\beta 1$ mRNA by 4 hours, which declined over the next 12-24 hours to initial levels (Figure 1C). Juglone consistently suppressed TGF- $\beta 1$ mRNA in both resting and HA-treated cells. To determine the significance of these effects, we measured active, intracellular, and secreted TGF- $\beta 1$ in the medium after 24 hours in culture. As seen for coding mRNA, Pin 1 inhibition significantly decreased active TGF- $\beta 1$ in both cells and medium (Figure 1, D and E). Therefore, Pin 1 regulates TGF- $\beta 1$ mRNA accumulation and cytokine release by activated Eos.

Pin 1 inbibition accelerates TGF- $\beta 1$ mRNA decay. TGF- $\beta 1$ expression is altered by various cytokines (IL-3, -4, and -5) (13) as well as other Eos agonists, including HA (Figure 1A) (14). However, the mechanisms underlying these effects are unknown. Given the prior work (19) and data shown above, we examined the role of Pin 1 in the regulation of TGF- $\beta 1$ mRNA stability. Cells were resting or activated with HA or HA plus juglone before transcription was blocked and the rate of TGF- $\beta 1$ mRNA decay measured by qPCR. In resting cells or those treated with HA alone, the decay of TGF- $\beta 1$ mRNA was moderately stable before Pin 1 blockade, but the half-life decreased from approximately 6 to approximately 3 hours after juglone treatment (Figure 1F). High-dose juglone (>7 $\mu \mathrm{M})$ partially inhibits RNA polymerase II (28). However, prior studies have shown that low-dose juglone $(1 \mu \mathrm{M})$ as used here had no effect on housekeeping mRNAs (actin, S26) or the transcriptional upregulation of IL-4 or eotaxin by activated Eos (29). Therefore, while juglone may affect transcription, these results strongly suggest Pin 1 selectively regulates TGF- $\beta 1$ mRNA stability.

$P K C-\alpha$ regulates TGF- $\beta 1 \mathrm{mRNA}$ and protein production. $\mathrm{PKC}-\alpha / \beta 1$ and ERK have been implicated in TGF- $\beta 1$ production by activated mesangial cells and $T$ lymphocytes $(15,16)$. These signaling cascades also play key roles in the posttranscriptional regulation of cytokine mRNAs (17). Therefore, we evaluated whether PKC- $\alpha / \beta 1$ and ERK were also involved in the regulation of TGF- $\beta 1$ in Eos. Treatment of activated Eos with Gö6976, a selective inhibitor for $\mathrm{Ca}^{2+}$-dependent PKC- $\alpha / \beta 1$ (30), or safingol, a selective inhibitor for $\mathrm{Ca}^{2+}$-dependent PKC- $\alpha$ (31) (Table 1), induced dose-dependent reductions in TGF- $\beta 1$ mRNA and protein, while PD98059, a MEK1 inhibitor, was only minimally effective even at the highest concentrations $(50 \mu \mathrm{M})$ (Figure 2, A and B). Consistent with ety of mitotic kinases (21). Therefore, we immunoprecipitated cell lysates with anti-Pin 1 followed by immunoblot with anti-PKC- $\alpha$. Indeed, PKC- $\alpha$ was consistently precipitated with Pin 1 (Figure 2D). Reverse immunoprecipitation with anti-PKC- $\alpha$ also brought down Pin1 (data not shown).

To better understand the regulatory direction of the Pin $1-\mathrm{PKC}-\alpha$ interaction, HA-activated Eos were treated either briefly (10 minutes) with juglone or Gö6976 or for 4 hours with juglone. Juglone covalently inactivates Pin 1 and within several hours accelerates its catabolism by the proteasome (19). There was no change in the amounts of either Pin 1 or PKC- $\alpha$ in Eos treated for 10 minutes with either juglone or Gö6976 (data not shown). However, PPIase activity was completely inhibited in Eos treated with Gö6976 (Figure 2E). Conversely, Pin1 PPIase activity was enhanced in Eos treated with PKC- $\alpha$ agonist 12(S)-HETE (Figure 2F) or TXA (data not shown) (Table 1). These results suggest that PKC- $\alpha$ is upstream of and necessary for Pin 1 activation in HA-treated Eos. After 4 hours of Pin 1 blockade, total and Pin1-associated PKC- $\alpha$ were significantly decreased, an effect that could be partially prevented by proteasome inhibitor MG132 (Figure 2, D and G) (36). These data suggest that Pin 1 protects PKC- $\alpha$ from catabolism by the proteasome. Therefore, PKC- $\alpha$ is upstream of Pin 1 activation, but Pin 1 is required to maintain cytosolic levels of PKC- $\alpha$.

Previously, we showed that Pin 1 was dephosphorylated by HA treatment, which increased isomerase activity (19). These data suggested that a phosphatase might be an intermediary between PKC- $\alpha$ and Pin1. As PP2A has been implicated in cytokine expression by mast cells via physical interaction with PKC- $\alpha$ (37), we immunoprecipitated cell lysates with anti-PKC- $\alpha$ or anti-Pin 1 followed by immunoblot with anti-PP2A. As shown in Figure 3A, PP2A was reproducibly coprecipitated by either antibody. Exposure of Eos (4 hours) to increasing concentrations of okadaic acid, a selective inhibitor for PP2A (Table 1), progressively reduced TGF- $\beta 1$ mRNA by $50 \%-80 \%$ (Figure 3B). Brief exposure of HA-activated Eos (10 minutes) to okadaic acid also reduced Pin 1 isomerase activity to the level seen in resting cells (Figure 3C), without altering Pin 1 or PP2A levels (Figure 3D). However, extended exposure to juglone triggered PP2A degradation (Figure 3E, 4 hours) as seen above for Pin 1 and PKC- $\alpha$ (Figure 2, D and G). Therefore, both PP2A and PKC- $\alpha$ are upstream of, interact with, and are required for Pin 1 activation. 

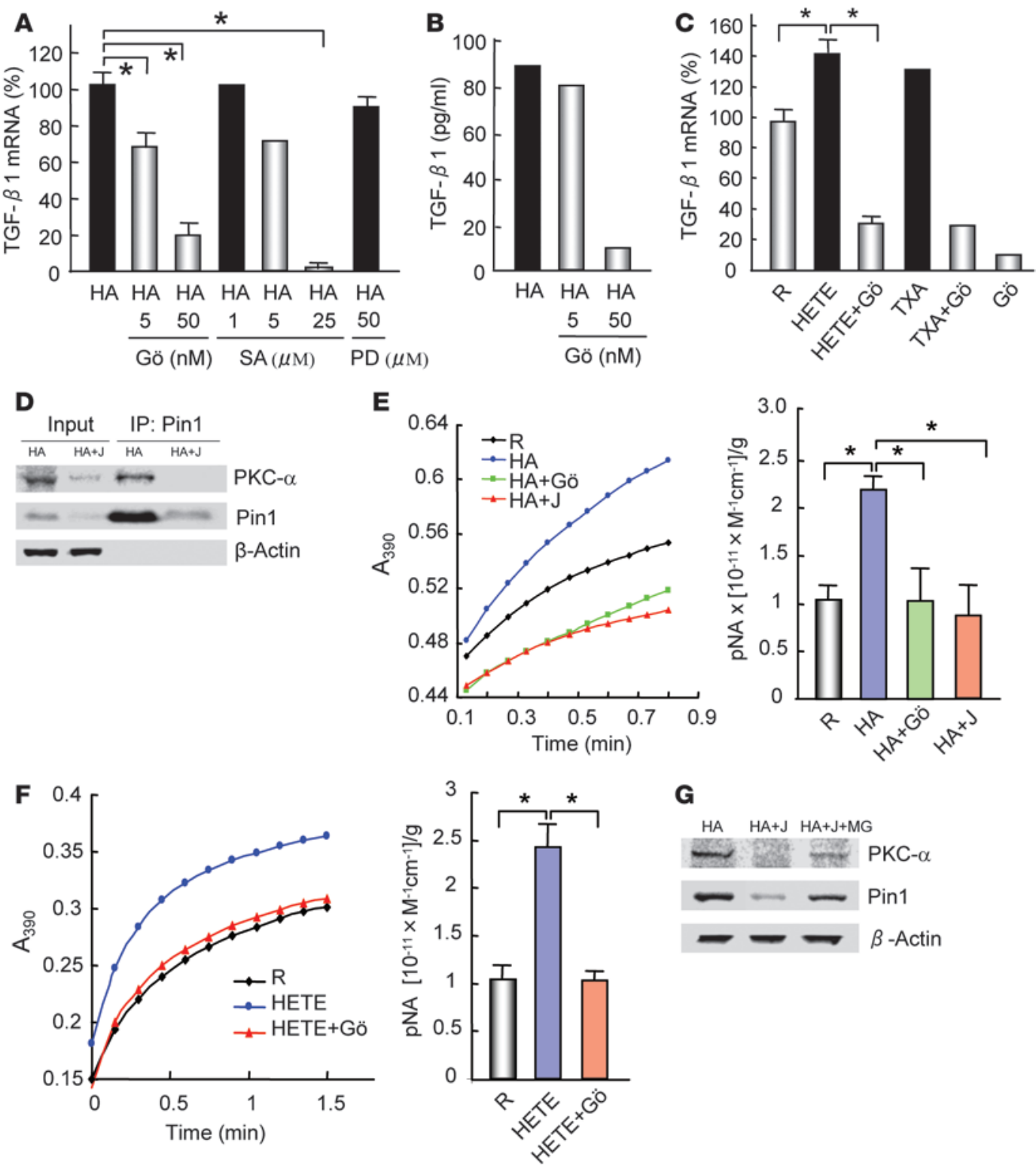

G

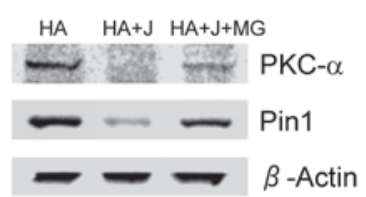

\section{Figure 2}

Pin1 associates with and is downstream of PKC- $\alpha$. (A and C) RT-qPCR analysis for TGF- $\beta 1$ mRNA. (A) Eos were treated as in Figure 1A. Gö, Gö6976; SA, safingol; PD, PD98059 $(50 \mu \mathrm{M})$. (B) ELISA for TGF- $\beta 1$ protein. Cells were treated as in Figure 1D. (C) Eos were treated as in A. HETE, 12(S)-HETE $(10 \mathrm{nM} / \mathrm{ml})$; TXA, thymeleatoxin $(10 \mathrm{nM})$. (D) Eos were treated for 4 hours with HA alone or with juglone. Lysates were immunoprecipitated with anti-Pin1 followed by immunoblotting (as shown on right). Input, $10 \%$ of lysates before IP. The blot represents 1 of 2 independent experiments. (E and F) Pin1 isomerase assay of cytoplasmic lysates from untreated Eos (R) or Eos treated for 10 minutes with $\mathrm{HA}$ alone, with juglone, or with Gö6976 (HA+Gö) (E) or with 12(S)-HETE alone or with Gö6976 (HETE+Gö) (F). The kinetics (left) is representative of 3 independent experiments. The released $\Delta[\mathrm{pNA}] / \mathrm{g}$ of protein was calculated (right), as described (20). (G) Immunoblot of cell lysates from Eos treated for 4 hours with HA alone or with juglone or with $50 \mu \mathrm{M}$ of MG132 (HA+J+MG). The blot represents 1 of 2 independent experiments. Error bars indicate mean \pm SD of 3 independent experiments with different donors. ${ }^{*} P<0.05$ by Student's $t$ test in a 2 -tailed analysis.

To clarify the signaling interactions between PKC- $\alpha$, PP2A, and Pin1, Eos were activated with the PKC- $\alpha$ agonist, 12(S)-HETE before treatment with okadaic acid. As shown (Figure 3, F and G), PP2A inhibition suppressed 12(S)-HETE-induced upregulation of Pin1 isomerase activity and subsequent TGF- $\beta 1$ expression. HA treatment selectively increased the interaction between PP2A and Pin1 without altering the amount of PKC- $\alpha$ bound to PP2A or Pin 1 (Figure $3 \mathrm{H})$. Therefore, Pin 1 forms binary or tertiary complexes with both PKC- $\alpha$ and PP2A, and both kinase and phosphatase activity are necessary for the upregulation of Pin1's PPIase. Conversely, the cytoplasmic stability of PKC- $\alpha$ and PP2A is dependent on Pin1, suggesting reciprocal regulation.

Pin1 modulates RNA-binding protein interactions with TGF- $\beta 1 \mathrm{mRNA}$. A variety of data have linked AREBPs to the control of cytokine mRNA decay. Both stabilizing (HuR, YB-1) and destabilizing AREbinding proteins (TTP, KH-type splicing regulatory protein [KSRP], 


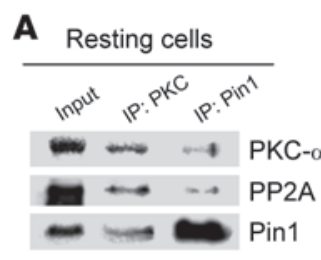

E

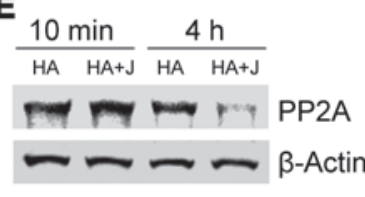

B

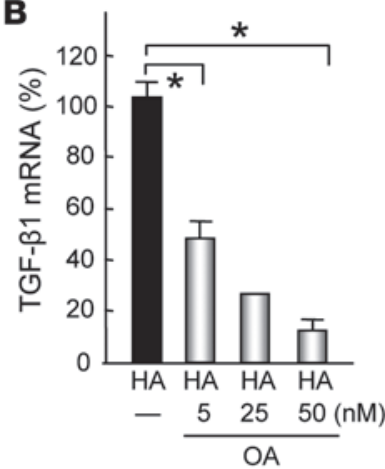

F

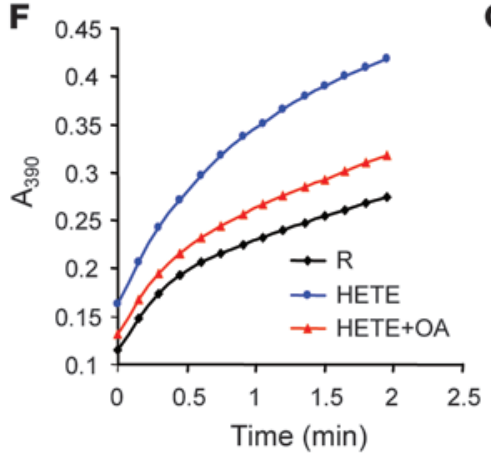

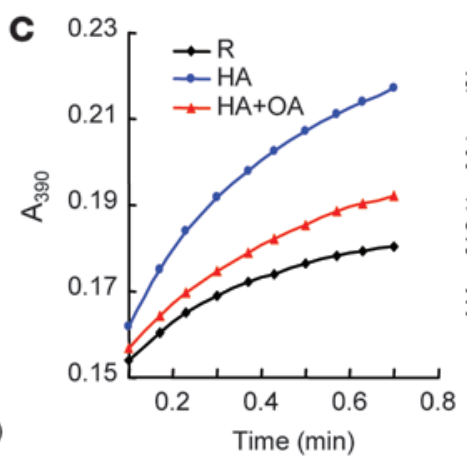

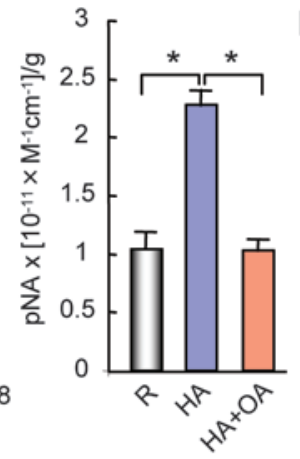

D HA+OA (4 h) - $\mathrm{PP} 2 \mathrm{~A}$ - Pin1 $\beta$-Actin

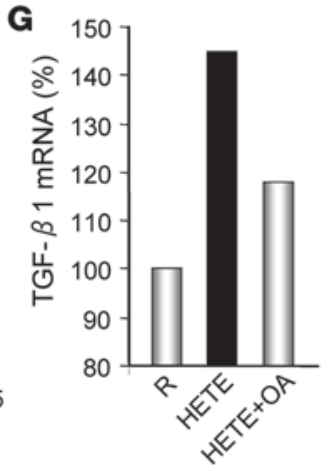

H

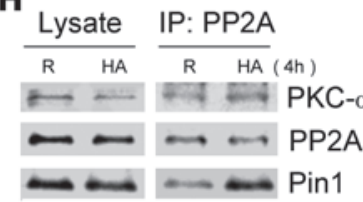

Figure 3

Pin1 associates with and is downstream of PP2A. (A) Lysates from resting cells were immunoprecipitated as described above (Figure 2D) followed by immunoblotting (antibodies, right margin). (B) RT-qPCR for TGF- 31 mRNA. Cells were treated as in Figure 2G. (C) Pin1 isomerase assay. Cells were treated as in Figure 1E. OA, okadaic acid (1 nM). (D and E) Immunoblot of cell lysates. Cells were treated as in $\mathbf{B}$ and immunoblotted with the antibodies shown. (F) Pin1 isomerase assay. Cells were treated as in $\mathbf{C}$ and Figure $2 \mathrm{~F}$. (G) RT-qPCR analysis for TGF- $\beta 1 \mathrm{mRNA}$. Eos were treated as in $\mathbf{F}$ for 4 hours. (H) Eos were left untreated or treated for 4 hours with HA. Cell lysates were immunoprecipitated with anti-PP2A followed by immunoblot. Lysate, $10 \%$ of lysates before immunoprecipitation. The data in $\mathbf{A}$ and $\mathbf{D}-\mathbf{H}$ represent 1 of 2 independent experiments. Error bars indicate mean \pm SD of 3 independent experiments with different donors. ${ }^{*} P<0.05$ by Student's $t$ test in a 2-tailed analysis.

and AUF1) (17) have been defined. Pin1 interacts with AUF1 and HuR and modulates their affinity for GM-CSF mRNA (19). As HuR (22) and AUF1 (23) have recently been implicated in TGF- $\beta 1$ gene regulation, we immunoprecipitated various ARE-binding proteins (YB-1, heterogeneous nuclear ribonucleoprotein $\mathrm{C}$ [hnRNP C], HuR, nucleolin, AUF1, T cell intracellular antigen 1 [TIA-1], TIA-1-related protein [TIAR], and TTP) from total cytoplasmic extracts followed by reverse transcription and qPCR for TGF- $\beta 1$ mRNA. Of those examined, HuR, AUF1, and TIA- 1 were reproducibly coprecipitated with TGF- $\beta 1 \mathrm{mRNA}$ in activated cells (Figure 4A). Exposure of cells to juglone significantly decreased the abundance of TGF- $\beta 1$ transcripts associated with HuR, while it substantially increased those bound to AUF1 and TIA-1. After normalization to the total amount of mRNA present, AUF1 and TIA-1 showed substantially higher binding efficiency after Pin 1 inhibition compared with HA-activated cells (Figure 4B). TGF- $\beta 1$ mRNA predominantly partitioned with HuR after HA (5.5\%), which modestly decreased (3.5\%) after juglone (Figure 4C). Much larger changes were seen after Pin 1 inhibition with both AUF1 (30-fold) and TIA-1 (200-fold). These data are consistent with the known functions of AUF1 (38) and TIA-1 as destabilizers (39) and HuR as an mRNA stabilizer (40) As TGF- $\beta 1$ is modestly stable despite interacting with AUF1 and TIA-1 after Pin 1 inhibition, we infer that the maintenance of HuR interactions counteracts a tendency to rapid decay. Therefore, our data suggest that TGF- $\beta 1$
mRNA selectively interacts with different ARE-binding proteins that are modulated by Pin 1 activity and depend on the activation state of the cell.

We next asked whether TGF- $\beta 1$ mRNA was catabolized by the exosome as observed with rapidly degraded cytokine mRNAs such as GM-CSF (19). Pin1 inhibition selectively increased p37AUF1 binding to exosome components (PMScl75), as well as to GMCSF mRNA (19). This suggested that p37AUF1 targets cytokine mRNAs to the exosome for rapid decay either in resting cells or after Pin 1 inhibition. Therefore, we measured TGF- $\beta 1$ mRNA in anti-PMScl75 pellets by qPCR. Consistent with this hypothesis, little TGF- $\beta 1$ mRNA was detected with the exosome in lysates from activated cells, but the level increased by 10 -fold after Pin 1 blockade (Figure 4D). This result suggests TGF- $\beta 1$ mRNA may be degraded by the exosome, which is modulated by Pin 1 .

$H u R$ and AUF1 catabolism is linked to Pin1. Previously, we noted that juglone accelerated AUF1 and Pin1 decay by the proteasome (19). HuR but not TIA-1 also showed reduced cytoplasmic levels after juglone (Figure 5A). These data suggested that AUF1 and HuR but not TIA-1 directly interacted with Pin 1. Immunoprecipitation revealed that HuR coprecipitated with Pin 1 but TIA-1 did not (Figure 5A), and HA treatment did not alter these interactions. Moreover, juglone treatment caused proteasomal degradation of HuR (Figure 5B) and reduced binding activity to TGF- $\beta 1$ mRNA (Figure 4B). These results are similar to those seen with p45, p42, 

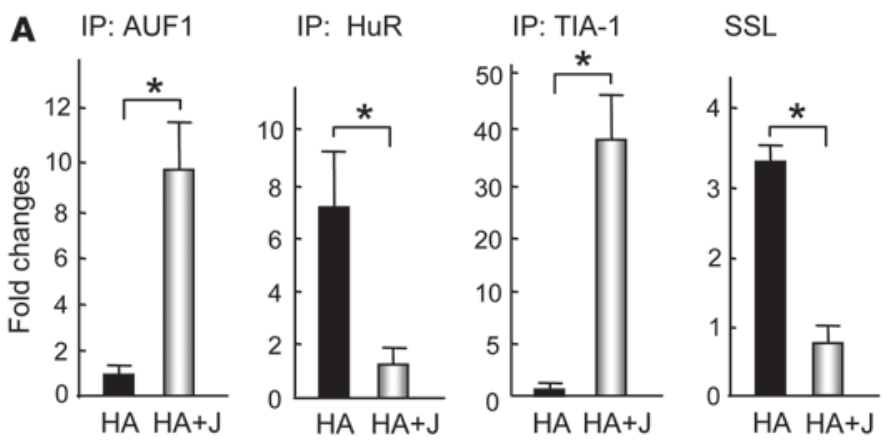

B AUF1/SSL
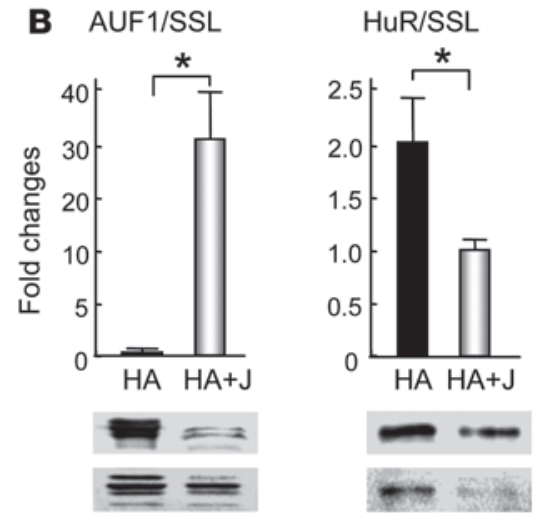

TIA-1/SSL
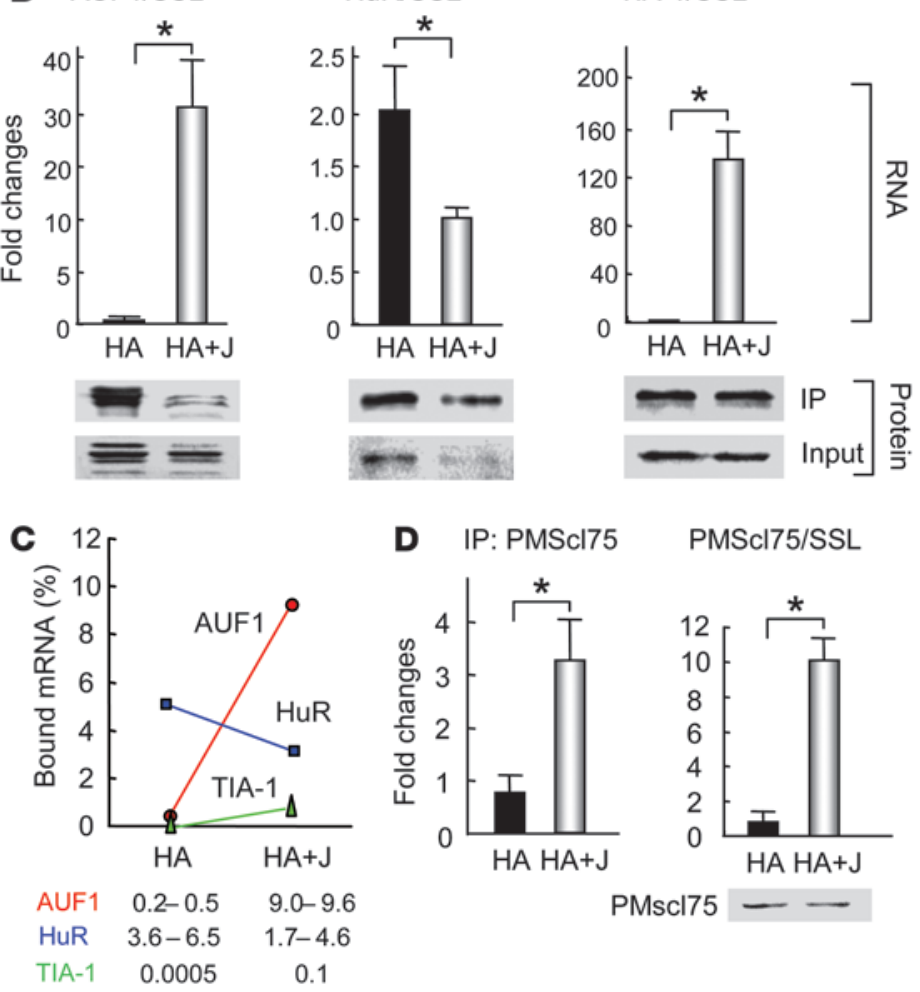

D IP: PMScl75

PMScl75/SSL
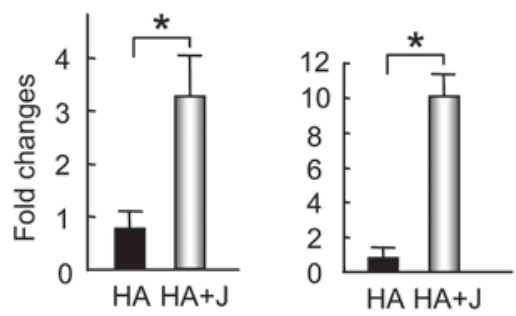

PMscl75 - -
Figure 4

TGF- $\beta 1$ mRNA partitions between different RNA-binding proteins. (A-D) RT-qPCR analysis for TGF- $\beta 1 \mathrm{mRNA}$. Cells were treated as in Figure 2A. After lysis, $50 \%$ was used for determination of steady-state level (SSL) of TGF- $\beta 1 \mathrm{mRNA}$, and the remainder was used for AUF1, HuR, TIA-1, or PMScl75 immunoprecipitation followed by RT-qPCR. ( $B$ and $\mathbf{D}$ ) The relative abundance of mRNA in each IP shown in $\mathbf{A}$ and $\mathbf{D}$ was normalized to SSL. $20 \%$ of lysate and IP pellets was used for immunoblot to represent the input and precipitated proteins (bottom). (C) The percentage of TGF- $\beta 1$ mRNA bound to each RNAbinding protein was calculated for each group (HA or HA+J). Data are the mean from 2 independent experiments. Error bars indicate mean \pm SD of 3 independent experiments with different donors. ${ }^{*} P<0.05$ by Student's $t$ test in a 2 -tailed analysis.

Pin 1 modulates TGF- $\beta 1$ expression by in vivo activated Eos. To address the in vivo relevance of Pin 1 in the regulation of TGF- $\beta 1$ in asthmatics, we obtained BAL Eos 2 days after segmental allergen challenge. Typically, more than $50 \%$ of the total cells are Eos that show an extremely activated effector phenotype, considerably prolonged in vitro survival (Figure 6A), and elevated Pin 1 isomerase activity (19) and are comparable to peripheral blood Eos fully activated in vitro with HA. If Pin 1 isomerase activity underlies increased cytokine expression, purified BAL Eos should show elevated PKC- $\alpha$ activity and TGF- $\beta 1 \mathrm{mRNA}$ and protein secretion. Cell lysates were analyzed for TGF- $\beta 1$ mRNA and protein, and secreted cytokine was measured by ELISA. Similar to in vitro activated Eos, we detected high levels of TGF- $\beta 1$ mRNA (at 4 hours) (Figure 6B) and secreted protein (at 24 hours) from BAL Eos (Figure 6C). PKC- $\alpha$ was nearly completely phosphorylated in BAL Eos (Figure 6D) compared with the minimal phosphorylation seen in peripheral blood Eos from healthy donors (data not shown). Ex vivo exposure of BAL Eos to juglone decreased the level of TGF- $\beta 1$ mRNA (by $50 \%$ in 4 hours) and active protein (by 50\% in 24 hours) in the culture medium (Figure 6C). Similarly, dominant-negative TAT-WW-Pin 1 also decreased TGF- $\beta 1$ mRNA to basal levels, while PKC- $\alpha$ or PP2A blockade had the most profound effects (Figure 6B), and ERK inhibition had modest effects (Figure 6B). As seen with Eos activated in vitro (Figure 2D), treatment with juglone for 4 hours reduced PKC- $\alpha$, while $\beta$-actin and Pin 1 remained unchanged (Figure 6D). After 24 hours of juglone, Pin 1 levels were significantly reduced, while $\beta$-actin remained constant throughout (Figure 6C). Finally, Pin 1 isomerase activity was also decreased after inhibition of Pin $1, \mathrm{PKC}-\alpha$, or PP2A (Figure $6 \mathrm{E})$. Collectively, these data suggest that the functional role of Pin 1 in the expression of TGF- $\beta 1$ is similar in in vivo and in vitro activated human Eos.

Pin1 blockade reduces TGF- $\beta 1$ and airway fibrosis in the lung of allergen-challenged animals. Our data predict that Pin 1 blockade should reduce airway TGF- $\beta 1$ production by activated Eos, thereby attenuating airway remodeling. To test this, we employed 2 wellestablished rodent models of asthma. Allergen-sensitized, acutely challenged (1 aerosol challenge) Brown Norway rats were used to evaluate the effects of Pin 1 inhibitors on airway eosinophilia and peribronchiolar collagen deposition, while $P$ in $1^{-/-}$mice were used to establish the effects of chronic allergen exposure. Rats were sensitized by subcutaneous injection of ragweed pollen extract (RAG) 


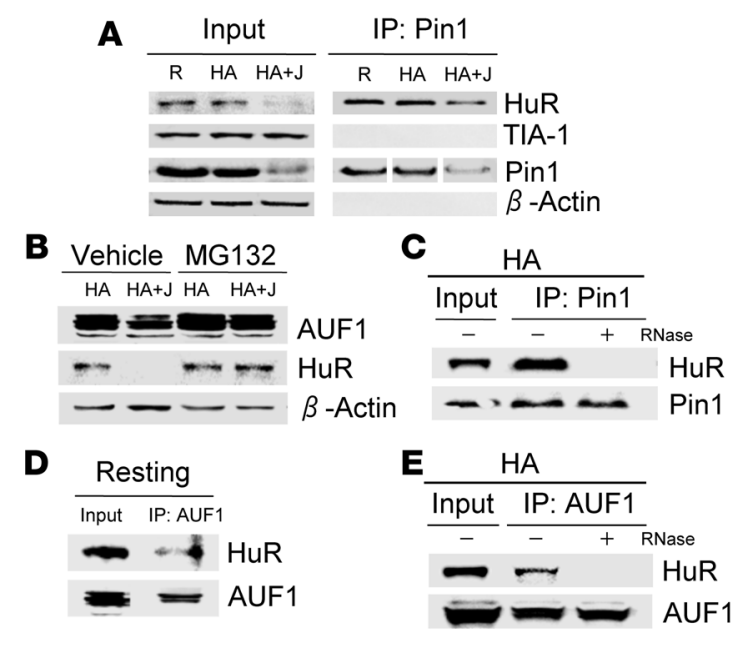

and 2 weeks later challenged once for 20 minutes with aerosolized vehicle (PBS) or $1 \%$ allergen (RAG). Some RAG-challenged rats received daily intraperitoneal juglone $(1 \mathrm{mg} / \mathrm{kg} / \mathrm{d}, \mathrm{RAG}+\mathrm{J})$ started the day before challenge. BAL fluid and lung tissue were assessed 2 days after challenge for inflammation, TGF- $\beta 1$, and collagen. BAL fluid and lung tissue from juglone-treated rats showed dramatic reductions in eosinophilia ( $>50 \%$ decrease) but no change in the number or subtype of infiltrating lymphocytes, neutrophils, or macrophages (Table 2) $(29,43)$. Levels of prosurvival GM-CSF and IL-5 were also reduced, while other cytokines (IFN- $\gamma$ and IL-3) were unchanged (29). After normalization to BAL cell numbers, the levels of TGF- $\beta 1$ and type I collagen mRNA (Figure 7A) as well as Pin 1 isomerase activity but not Pin1 levels (29) (data not shown) were also significantly reduced by juglone. Quantitation with ImageJ software of 15 midsized bronchioles stained with trichrome showed significantly greater fibrosis in sensitized and challenged rats (RAG) than in those treated with Pin1 inhibitors $(\mathrm{RAG}+\mathrm{J})($ Figure $7 \mathrm{~B})$. Consistent with these data, type I and III collagen mRNAs were significantly reduced in lung tissue (Figure 7C) from juglone-treated animals compared with untreated controls.

To evaluate the role of Pin 1 in chronic allergen exposure, peribronchiolar fibrosis, and remodeling, $\operatorname{Pin}^{-/ /}$or $\mathrm{Pin}^{1^{+/}}$littermates were sensitized to OVA and, 2 weeks later, challenged 3 times a week for 4 weeks with $1 \%$ aerosolized allergen. After sacrifice, anti-

\section{Figure 6}

Pin1 regulates TGF- $\beta 1$ expression by in vivo activated Eos. (A) Viability of Eos after 3 day of culture. Purified Eos from BAL fluid (BAL Eos) were obtained from patients 2 days after segmental allergen challenge. Control peripheral blood Eos (PB Eos) were obtained from healthy donors. (B) RT-qPCR analysis for TGF- $\beta 1$ mRNA. BAL Eos were left untreated (-) or incubated for 4 hours with juglone, $300 \mathrm{nM}$ TAT-WW-Pin1, 300 nM TAT-GFP, 50 nM Gö6976, 5 nM okadaic acid, or $50 \mu \mathrm{M}$ PD98059. (C) Cells left untreated or incubated for 24 hours with juglone before collection of culture medium and cells for ELISA and immunoblot. (D) Cells left untreated or treated for 10 minutes or 4 hours with juglone. Cytoplasmic lysates were immunoblotted. (E) Pin1 isomerase assay of cytoplasmic lysates from cells nontreated (NT) or treated for 4 hours with Gö6972 (5 nM), okadaic acid (5 nM), or juglone. Data in $\mathbf{E}$ are representative of 2 independent experiments. Error bars $(\mathbf{A}$ and $\mathbf{B})$ indicate mean \pm SD of 3 independent experiments with different donors. ${ }^{*} P<0.05$ by Student's $t$ test in a 2-tailed analysis.

\section{Figure 5}

Pin1-AREBP interactions are partially RNA dependent and terminated by the proteasome. (A) Cells were left untreated or treated for 4 hours with $\mathrm{HA}$ alone or with juglone. Cell lysates were immunoprecipitated with anti-Pin1 followed by immunoblotting with the antibodies shown. Input, $10 \%$ of lysates before immunoprecipitation. (B) Immunoblot of cytoplasmic proteins from Eos treated for 4 hours with HA alone, with juglone, or with $50 \mu \mathrm{M}$ of MG132. (C) Cells were treated for 4 hours with $H A$. Cytoplasmic lysates were treated with or without RNAse $(A+T 1)$ before immunoprecipitation with anti-Pin1 followed by immunoblotting. Input, $10 \%$ of lysates before immunoprecipitation. (D) Resting cells were immunoprecipitated with anti-AUF1 followed by immunoblotting. (E) Cells treated as in $\mathbf{C}$ before immunoprecipitation with anti-AUF1 followed by immunoblotting. Representative data from 3 donors are shown.

OVA IgE levels were equally elevated in knockout and wild-type mice (data not shown), indicating successful and equivalent sensitization. Fixed lung sections stained with trichrome and analyzed by ImageJ software showed significant reductions in peribronchial collagen content in Pin1-knockout mice compared with wild-type controls (Figure 7D). BAL and parenchymal inflammation as well as TGF- $\beta 1$ and collagen mRNA levels had returned to base-

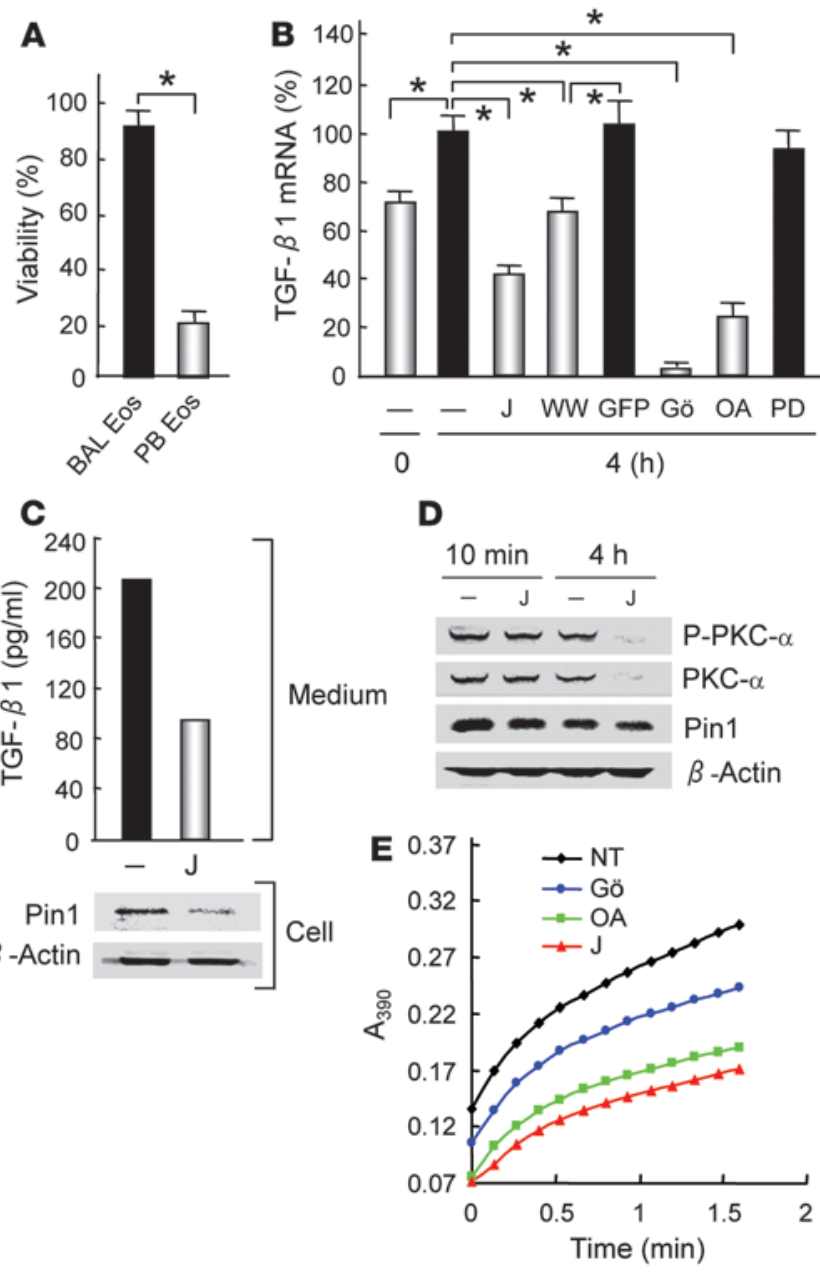




\section{Table 2}

BAL cell numbers and differential

\begin{tabular}{lccc} 
& PBS & RAG & RAG+J \\
Total cells & $508 \pm 139(348-736)$ & $3,458 \pm 1,770(1,150-5,590)^{\mathrm{A}}$ & $1,878 \pm 752(650-2,740)$ \\
Eos & $15 \pm 13(0-35)$ & $2,358 \pm 1,732(886-4,807)^{\mathrm{A}}$ & $531 \pm 343(36-939)^{\mathrm{B}}$ \\
Macrophages & $490 \pm 149(310-732)$ & $871 \pm 493(167-1,506)$ & $1,099 \pm 314(595-1,576)$ \\
Lymphocytes & $2 \pm 3(0-8)$ & $105 \pm 82(48-267)^{\mathrm{A}}$ & $127 \pm 128(3-343)$ \\
Neutrophils & $2 \pm 2(0-4)$ & $130 \pm 99(29-307)^{\mathrm{A}}$ & $124 \pm 120(16-347)$ \\
\hline
\end{tabular}

Pin1 blockade selectively reduces eosinophilia. Rats were sensitized but challenged with diluent (PBS) or subjected to allergen challenge without (RAG) or with juglone treatment (RAG+J) as in Figure 7. Numbers of cells were determined. Data are presented as mean $\left(\times 10^{-3}\right) \pm S D$ (range). ${ }^{A} P<0.05$ between PBS and RAG by Mann Whitney $U$ test; ${ }^{B} P<0.05$ between RAG and RAG+J; 6 rats/group.

PKC- $\alpha$ physically interact in mast cells (37) and reciprocally modulate each other (47). Direct PKC- $\alpha$ activation with $12(\mathrm{~S})$-HETE increased Pin 1 PPIase activity and TGF- $\beta 1$ mRNA expression, which was almost entirely suppressed by okadaic acid (Figure 3, F and $G$ ). In addition, the interaction between Pin 1 and PP2A was increased by cell activation (Figure $3 \mathrm{H}$ ). As PKC- $\alpha$ may control PP2A activity (47-49), we propose that the sequential activation of coassociated PKC- $\alpha$ and PP2A modulates

line (data not shown) at the time of analysis, consistent with the development of tolerance induced by repetitive allergen exposure (44). Therefore, based on the results shown here, Pin 1 blockade attenuates pulmonary eosinophilia and both acute and chronic bronchiolar remodeling induced by allergen challenge.

\section{Discussion}

Airway fibrosis is a common complication of chronic asthma. This process is driven in part by the overproduction of TGF- $\beta 1(5,11)$ and other profibrotic mediators released by lung parenchyma as well as activated inflammatory cells (6). Eos are a major contributor to the profibrotic milieu within the asthmatic lung (4). Despite its importance, little is known regarding the mechanisms that underlie the production of TGF- $\beta 1$ by activated Eos.

Here we document for the first time to our knowledge that Pin1 is a critical mediator of TGF- $\beta 1$ mRNA stability and cytokine production in either in vivo or in vitro activated Eos. Pin 1 regulates cytokine production at a posttranscriptional level by modulating the binding affinity, catabolism, and protein-protein interactions of multiple RNA-binding proteins, including AUF1, HuR, and TIA-1. Pin 1 itself is controlled by PKC- $\alpha$ along with PP2A, which binds to and modulates PPIase activity in response to external stimulation. These observations have in vivo relevance, as Pin 1 blockade or genetic ablation significantly reduced TGF- $\beta 1$ production, collagen accumulation, and airway remodeling in animal models of asthma. Therefore, these findings are of considerable importance for understanding and possibly preventing fibrotic airway disease.

Using multiple pharmacological inhibitors and activators (Table 1) and immunoprecipitation, we identified PKC- $\alpha$ and PP2A as probable upstream regulators of Pin 1 in Eos. Inhibition of either PKC- $\alpha$ or PP2A mimicked the effect and kinetics of juglone on Pin 1 isomerase activity (Figure $2 \mathrm{E}$ and Figure $3 \mathrm{C}$ ) and TGF- $\beta 1 \mathrm{mRNA}$ steady-state levels (Figure 1A, Figure 2A, and Figure 3B). Although we have only measured mRNA decay after juglone, the rapid and quantitatively similar reduction in TGF- $\beta 1 \mathrm{mRNA}$ after PKC- $\alpha$ and PP2A inhibition suggests a similar mechanism (45). In support of our findings, TGF- $\beta 1 \mathrm{mRNA}$ levels were rapidly altered (15, $16)$ by PKC- $\alpha$ signaling in mesangial cells and T lymphocytes. Conventional PKCs (PKC- $\alpha,-\beta 1,-\beta \mathrm{II}$, and $-\xi)$ are highly expressed by Eos (46), and PKC- $\alpha$ was heavily phosphorylated in BAL Eos after allergen challenge (Figure 6D). As juglone failed to alter PKC- $\alpha$ phosphorylation, our data suggest that Pin 1 does not modulate PKC- $\alpha$ activity. However, as dephosphorylation of Ser 16 within the WW domain activates Pin1 (21), downstream phosphatases such as PP2A are likely participants in the regulation of Pin1. PP2A and
Pin 1 isomerase activity in our system (50). How PKC- $\alpha$ alters PP2A is unknown but presumably involves phosphorylation. Interestingly, phosphorylation of PP2A has been associated with decreased rather than increased phosphatase activity (51).

TGF- $\beta 1$ mRNA lacks multiple AREs, which are found in the $3^{\prime}$ UTRs of posttranscriptionally regulated cytokine mRNAs. The exosome is generally considered to be the site for ARE mRNA decay (52). Our data demonstrate that cytokine mRNAs lacking multiple AREs decay at an intermediate rate and can be catabolized by the exosome as well. In addition, the observation that non-ARE-containing cytokine mRNAs can be regulated by AUF1 and HuR suggests considerable wobble in their target specificity. Previously we showed that Pin 1 interacts with AUF1 and HuR in Eos and T cells and regulates the interaction of these AREBPs with GM-CSF mRNA $(19,20)$. Here, we extended those observations by demonstrating a similar interaction between Pin1, AUF1, and TGF- $\beta 1$ mRNA (Figure 8). AUF1 recognizes and binds multiple AU- and CU-rich regions as well as stem-loop structures (53). Mutational analysis has shown that AUF1 bound with high affinity and specificity to UUAUUUUAU motifs in the $3^{\prime}$ UTR of phosphoenolpyruvate carboxykinase (PCK-6) mRNA (53). Deletion of this sequence resulted in dramatically increased half-life (5-fold) of mutant transcripts. TGF- $\beta 1$ mRNA contains a similar 3' UTR sequence (CUAUUUUAU), which may be the binding site of AUF1. Similarly, computational analysis has identified 3 putative HuR motifs, 2 located in the coding region and 1 in the $3^{\prime}$ UTR of TGF- $\beta 1$ mRNA (18) (Figure 8). Therefore, HuR and AUF1 may bind TGF- $\beta 1 \mathrm{mRNA}$ on distinct and nonoverlapping sites. In support of this idea, we observed simultaneous RNA-binding protein interactions with TGF- $\beta 1 \mathrm{mRNA}$ in cells treated with juglone (Figure $5 \mathrm{E}$ and Figure $4 \mathrm{~B}$ ). This is consistent with recent work showing the binding of both AUF1 and HuR to p21 and cyclin D1 mRNAs (42). Many ARE-binding proteins contain potential isomerization sites. Of those, Pin1 directly interacts with AUF1 (19) and indirectly via RNA with HuR (Figure 5C). Despite Ser-Pro sites, TIA-1 is not a ligand of Pin1 (Figure 5A). Therefore, we propose that only changes in AUF1 affinity are directly mediated by Pin 1 isomerization. Activated Pin1, by isomerizing hyperphosphorylated AUF1 isoforms, likely decreases AUF1 binding affinity for TGF- $\beta 1$ mRNA, which attenuates exosome-mediated decay (19). As AUF1 controls the decay of many other mRNAs, this mechanism may apply to them as well. TIA- 1 associates with TGF- $\beta 1$ mRNA after exosome delivery, while HuR may act as a brake on this process, leading to the intermediate decay rate observed after Pin 1 blockade. We have summarized these interactions in Figure 8. 
A

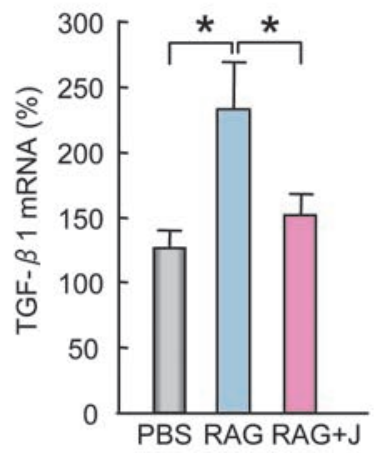

B

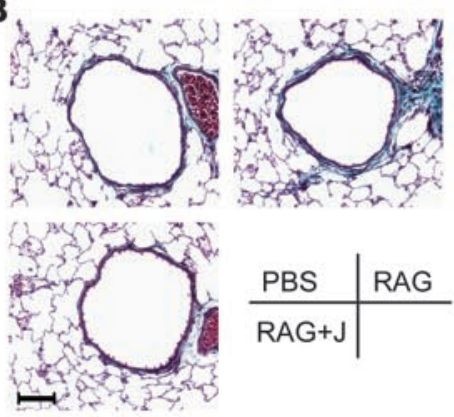

C

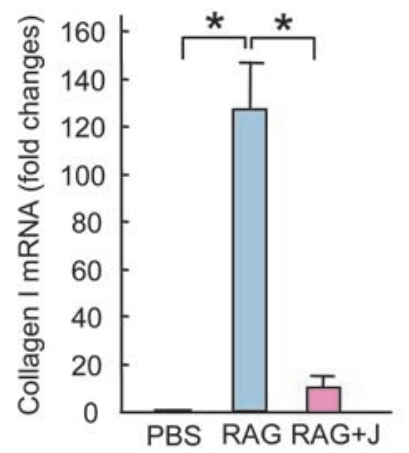

D

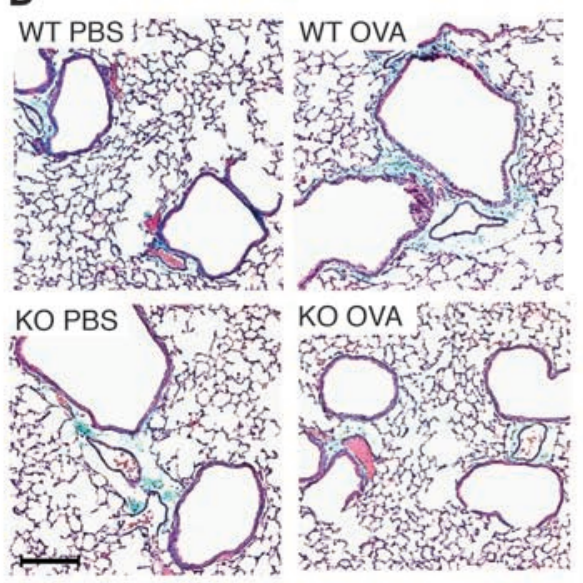

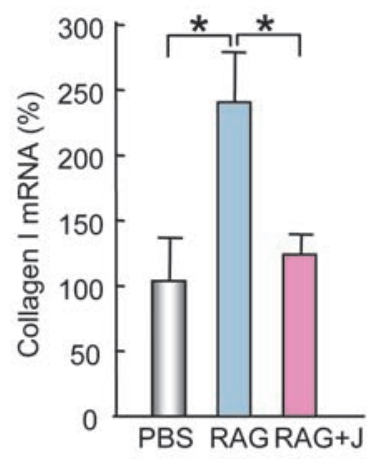
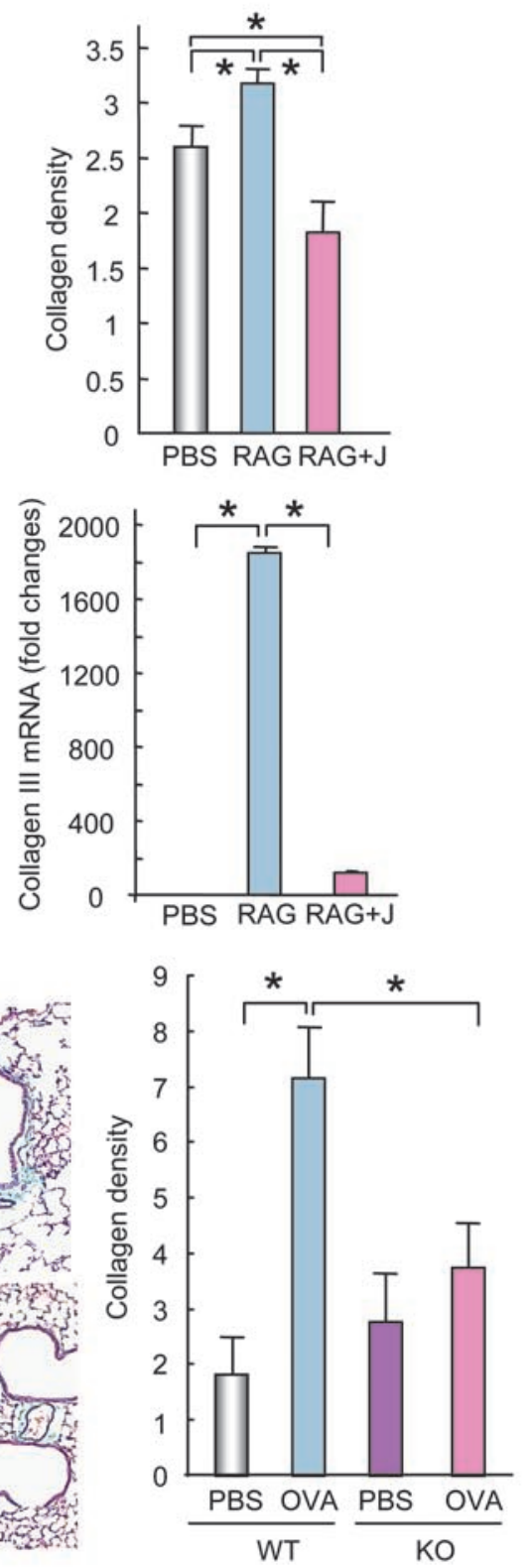

\section{Figure 7}

Pin1 blockade prevents peribronchiolar collagen deposition. (A-C) Rats were sensitized but challenged with vehicle (PBS) or subjected to allergen challenge without (RAG) or with juglone treatment (RAG+J) as described in Methods. (A) BAL fluid cells were collected, and the expression of TGF- $\beta 1$ and collagen I mRNA was measured by qPCR. (B) Lung fibrosis was evaluated by trichrome staining and image analysis. Scale bar: 100 $\mu \mathrm{m}$. (C) Lung collagen I and III mRNA expression was measured by qPCR. (D) Pin1-knockout and wild-type mice were sensitized but challenged with vehicle (PBS) or subjected to chronic allergen challenge with OVA as described in Methods. Lung fibrosis was evaluated by trichrome staining and image analysis. Scale bar: $100 \mu \mathrm{m}$. Error bars indicate mean \pm SD of 3-6 animals per group. Data are representative of at least 2 independent experiments. ${ }^{*} P<0.05$ by Student's $t$ test in a 2-tailed analysis.

way fibrosis $(2,3)$. These data strongly suggest that Eos are critically involved in airway remodeling and that targeted therapy could reduce this long-term sequela of asthma. Juglone-treated, challenged rats showed substantial reductions in airway Eos as well as their expression of TGF- $\beta 1$. Downstream collagen gene expression and ECM deposition in airways was also largely suppressed in both acute and chronic asthma models. In the acute rat model, the infiltration of other immune cells was unaffected, suggesting a relatively selective effect on Eos. In vitro exposure to juglone or dominant-negative TAT-WW-Pin1 induced Eos apoptosis but had no effect on lymphocyte survival (43). While the prodeath effects of low-dose juglone $(0.1 \mu \mathrm{M})$ could be antagonized by exogenous GM-CSF, higher-dose juglone could not $(19,29)$. These data suggest that Pin 1 is involved in both the production (19) as well as downstream, prosurvival signaling of GM-CSF. Therefore, it is likely that attenuated Eos inflammation observed here after Pin 1 blockade reflects enhanced apoptosis (29). The combination of reduced airway Eos and attenuated TGF- $\beta 1$ expression likely combine to reduce collagen production and airway remodeling in allergen-challenged animals. These data further support the concept that Eos are critical in airway remodeling and that the use of Pin 1 inhibitors may be an important advance to delay or attenuate this process in chronic asthmatics.

\section{Methods}

Reagents. HA was purchased from ICN Pharmaceuticals. Juglone was from Sigma-Aldrich. PKC- $\alpha /$ PKC- $\beta 1$ inhibitor Gö6976 was from Calbiochem. MEK1 inhibitor (PD98059) was from New England Biolabs. Anti-PKC- $\alpha$ (clone MC5) was from Abcam. Anti-phospho-PKC- $\alpha$ was from Cell Signaling. Anti-PP2A (clone 46) was from BD Biosciences. Anti-Pin 1 and anti-TIA-1 were from Santa Cruz Biotech-

Within a few days of allergen challenge, Eos increase by 20 - to 150 -fold in both humans and animals (Table 2) $(54,55)$. Depletion of Eos in humans with systemic steroids or anti-IL-5 or reduction of TGF- $\beta 1$ expression in animal models markedly attenuated air- nology Inc. and R\&D. Polyclonal anti-AUF1 was from Upstate Biotechnology. Anti-HuR (clone 19F12) was from Molecular Probes (Invitrogen). Anti-PMScl75 was from J. Wilusz (Robert Wood Johnson Medical School, Piscataway, New Jersey, USA). 


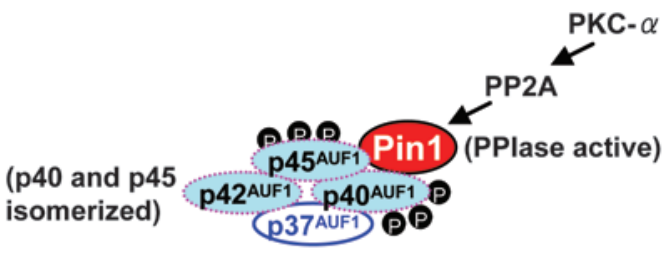

${ }^{7 m} \mathbf{G}$

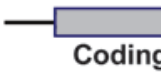

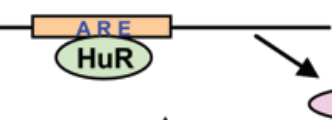
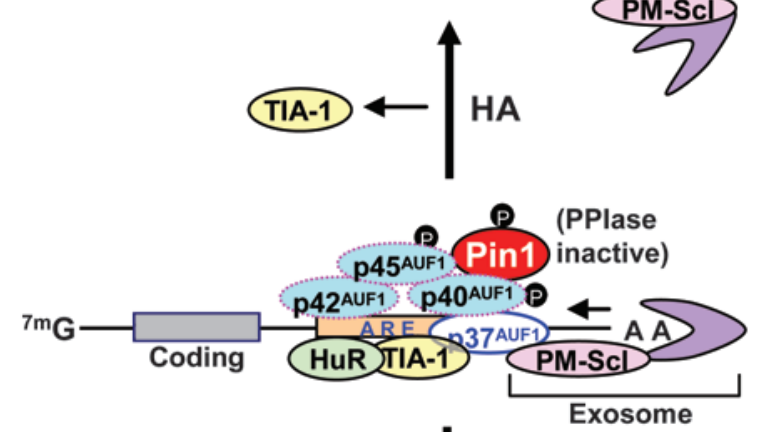

$\mathrm{HA}+\mathrm{J}$
A A A A A
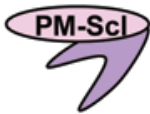

TGF mRNA stable

Basal condition

\section{Figure 8}

Summary of the changes in TGF- $\beta 1$ mRNA-AREBP interactions as a function of $\mathrm{HA}$ or $\mathrm{HA}$ plus juglone. Under basal conditions (middle), TGF- $\beta 1$ mRNA is associated with 4 partially phosphorylated AUF1 isoforms, HuR, TIA, hyperphosphorylated Pin1, and the exosome. HA treatment (top) causes the dephosphorylation and activation of Pin1 through the combined effects of PKC $\alpha$ and PP2A. Active Pin1 isomerizes AUF1, causing the release of TGF- $\beta 1$ mRNA and loss of exosomal targeting. Under these conditions, TGF- $\beta 1$ mRNA is predominantly associated with $\mathrm{HuR}$, leading to stabilization and translation. When Pin 1 is inactivated by covalent modification (juglone treatment, bottom), Pin1 and p45-, p42-, and p40AUF1 are rapidly catabolized by the proteasome, leaving TGF- $\beta 1$ mRNA bound by p37 AUF1, TIA, HuR, and the exosome. This complement of proteins accelerates TGF- $\beta 1$ mRNA decay and reduces TGF- $\beta 1$ expression.

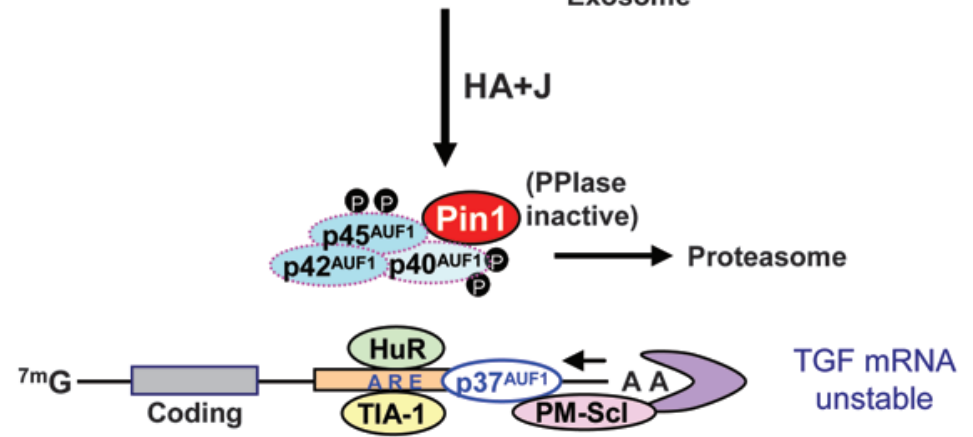

Subjects and Eos preparation. Peripheral blood was obtained by venipuncture from normal or mildly atopic donors. Peripheral blood or BAL fluid Eos were purified with a negative immunomagnetic procedure as described previously (56). Cells were used only when they were more than $99 \%$ pure. After isolation, Eos were cultured at $37^{\circ} \mathrm{C}$ in a humidified atmosphere of $5 \% \mathrm{CO}_{2}$ and $95 \%$ air at a density of $1 \times 10^{6} \mathrm{cells} / \mathrm{ml}$ in RPMI- 1640 medium, $10 \% \mathrm{FBS}$, and $50 \mu \mathrm{g} / \mathrm{ml}$ gentamicin (all from Life Technologies). All participants have a clinical record at the University of Wisconsin Hospital and informed consent was obtained according to approved University of Wisconsin Hospital Institutional Review Board protocol.

Rats and Pin 1-- mice. Male BN/SsN rats were purchased from Harlan and housed in HEPA-filtered isolation cubicles in an Association for Assessment and Accreditation of Laboratory Animal Care-accredited animal facility. Pin $1^{+/-}$mice on a C57BL/6J background were obtained from T. Means (Duke University, Durham, North Carolina, USA). Heterozygous pairs were bred to produce homozygous offspring. All animal procedures conformed to the Guide for the Care and Use of Laboratory Animals and were approved by the University of Wisconsin Animal Care and Use Committee. All husbandry and genotype determination of Pin1-knockout mice were performed in accordance with NIH and an approved University of Wisconsin-Madison animal care protocols as previously described $(29,43)$.

Sensitization and allergen challenge and juglone treatments of rats. BN/SsN rats, 10-13 weeks of age, were sensitized to short RAG (Hollister-Stier Laboratories) by a single subcutaneous injection of extract ( $1 \mathrm{mg}$ of protein) combined with adjuvant (Imject Alum; Pierce Biotechnology) 2 weeks before being challenged with either aerosolized short RAG ( $2 \% \mathrm{wt} / \mathrm{vol}$ solution in
PBS) or PBS alone for 20 minutes as described previously (57). On the day before, the day of, and the day after the aerosol challenge, rats received an intraperitoneal injection of juglone ( $1 \mathrm{mg} / \mathrm{kg}$ body weight $/ \mathrm{d}$; Calbiochem) or vehicle. Juglone was dissolved in ethanol $(2.4 \mathrm{mg} / \mathrm{ml}$ stock solution) and diluted with PBS to obtain a dose of $1 \mathrm{mg} / \mathrm{kg}$ body weight in a final volume of $5 \mathrm{ml}$ per injection. Control injections contained $5 \mathrm{ml}$ of vehicle. Two days after the aerosol challenge, BAL of the right lung and processing of the BAL cells were performed as described previously. After BAL, either the lungs were fixed with $10 \%$ buffered formalin by filling to total lung capacity by gravity or the right lung was excised and snap frozen in liquid nitrogen and crushed with a mortar and pestle. mRNA was analyzed as previously described (19). Paraffin sections of the right lung were prepared and stained with trichrome.

Sensitization and allergen challenge of $\mathrm{Pin}^{-/-}$mice. For the chronic asthma model, knockout or wild-type mice were sensitized by intraperitoneal injection of $20 \mu \mathrm{g}$ OVA (grade V; Sigma-Aldrich) emulsified in $2.25 \mathrm{mg}$ adjuvant (Imuject Alum; Pierce) in a total volume of $100 \mu \mathrm{l}$ on days 0 and 14 . One week after the last sensitization, mice were challenged with $1 \%$ aerosolized OVA for 20 minutes 3 times a week for 4 consecutive weeks (58).

Histological assessment of airway collagen. Paraffin sections of the lung tissue were prepared and stained using a modified trichrome stain with Alcian blue as described previously (59). The area and intensity of peribronchial trichrome staining was outlined and quantified using a light microscope and ImageJ software (http://rsb.info.nih.gov/ij/). Results are expressed as the area and intensity of trichrome staining per micrometer length of basement membrane of bronchioles with 200-350 $\mu \mathrm{m}$ internal 
diameters for rat and $150-200 \mu \mathrm{m}$ for mice. At least 15 bronchioles were counted for statistics.

Reverse transcription and real-time PCR. RNA was extracted with TriReagent (Molecular Research Center). cDNA quantitative PCR was performed in a SYBR PCR master (Applied Biosystems). An ABI 7500 thermocycler (Applied Biosystems) was used for 45 cycles of PCR. $\Delta$ Ct calculates the differences between target $\mathrm{Ct}$ values and the normalizer (housekeeping gene) for each sample: $\Delta \mathrm{Ct}=\mathrm{Ct}$ (target) $-\mathrm{Ct}$ (normalizer). The comparative $\Delta \Delta \mathrm{Ct}$ calculates the differences between each sample $\Delta \mathrm{Ct}$ value and the baseline $\Delta \mathrm{Ct}$. The comparative expression level (fold changes) was obtained by transforming the logarithmic values to absolute values using $2^{-\Delta \Delta C t}$.

Immunoprecipitation and immunoblot. These were performed as described previously (19). For experiments requiring RNAse treatment, RNAse A (10 $\mu \mathrm{g} / \mathrm{ml})$ and RNAse T1 (100 U/ml; both from Calbiochem) were added to the lysates immediately after preparation. Protein G-agarose beads were added, and the incubation was continued overnight. Pellets were washed 4 times with lysis buffer, and the beads were dissolved in TriReagent for RNA extraction or dissolved in SDS-PAGE loading buffer for immunoblotting.

Cytokine assay. Eos $\left(1 \times 10^{6} /\right.$ well $)$ were cultured in RPMI- 1640 containing $10 \%$ FBS to measure TGF- $\beta 1$. Supernatants were collected at 24 hours and stored at $-80^{\circ} \mathrm{C}$ until assayed. TGF- $\beta 1$ proteins released into culture supernatants were assessed using ELISA kits from R\&D Systems. The sensitivity of detection was $7 \mathrm{pg} / \mathrm{ml}$.

Recombinant TAT proteins. The cDNA encoding GFP or the WW domain of Pin 1 (provided by K.P. Lu, Harvard University, Boston, Massachusetts,
USA) was cloned in-frame into pHisTAT $(19,27)$. Proteins were expressed in E. coli and were purified on a $\mathrm{Ni}^{2+}$ chelate column (QIAGEN) as described by the manufacturer. Both TAT-linked proteins were more than $90 \%$ pure, based on Coomassie blue staining of SDS gels.

Pin1 activity assay. Activity was measured as described previously (24) with slight modifications $(19,20)$.

Statistics. Two-tailed Student's $t$ test was used. All data are represented as mean $\pm \mathrm{SD} ; n=3-5 . P<0.05$ was considered significant.

\section{Acknowledgments}

We thank J. Sedgwick for Eos; K.P. Lu for the Pin1 WW domain cDNA; J. Wilusz for anti-PM-Scl75; N. Jarjour for bronchoscopy samples; Zhi-Jian Zhang (University of Wisconsin-Madison) for microscopy assistance; and members of our laboratory and the UW-Asthma SCOR group for helpful suggestions. This work was supported by the NIH (P30HD03352 to J.S. Malter and P50HL56396 to J.S. Malter and R.L. Sorkness).

Received for publication May 24, 2007, and accepted in revised form October 31, 2007.

Address correspondence to: James S. Malter, University of Wisconsin, 509T Waisman Center, 1500 Highland Avenue, Madison, Wisconsin 53705, USA. Phone: (608) 262-8888; Fax: (608) 265-0367; E-mail: jsmalter@wisc.edu.
1. Kay, A.B., Phipps, S., and Robinson, D.S. 2004. A role for eosinophils in airway remodeling in asthma. Trends Immunol. 25:477-482.

2. Gharaee-Kermani, M., and Phan, S.H. 1998. The role of eosinophils in pulmonary fibrosis. Int. J. Mol. Med. 1:43-53.

3. Flood-Page, P., et al. 2003. Anti-IL-5 treatment reduces deposition of ECM proteins in the bronchial subepithelial basement membrane of mild atopic asthmatics. J. Clin. Invest. 112:1029-1036.

4. Humbles, A.A., et al. 2004. A critical role for eosinophils in allergic airways remodeling. Science. 305:1776-1779.

5. Minshall, E.M., et al. 1997. Eosinophil-associated TGF-beta 1 mRNA expression and airways fibrosis in bronchial asthma. Am. J. Respir. Cell Mol. Biol. 17:326-333.

6. Wahl, S.M., et al. 1987. Transforming growth factor type beta induces monocyte chemotaxis and growth factor production. Proc. Natl. Acad. Sci. U. S. A. 84:5788-5792.

7. Postlethwaite, A.E., Keski-Oja, J., Moses, H.L., and Kang, A.H. 1987. Stimulation of the chemotactic migration of human fibroblasts by transforming growth factor beta. J. Exp. Med. 165:251-256.

8. Franitza, S., et al. 2002. TGF-beta1 enhances SDF1alpha-induced chemotaxis and homing of naive $\mathrm{T}$ cells by up-regulating CXCR4 expression and downstream cytoskeletal effector molecules. Eur. J. Immunol. 32:193-202.

9. McMillan, S.J., Xanthou, G., and Lloyd, C.M. 2005. Manipulation of allergen-induced airway remodeling by treatment with anti-TGF-beta antibody: effect on the Smad signaling pathway. J. Immunol. 174:5774-5780.

10. Kenyon, N.J., Ward, R.W., McGrew, G., and Last, J.A. 2003. TGF-beta1 causes airway fibrosis and increased collagen I and III mRNA in mice. Thorax. 58:772-777.

11. Sime, P.J., Xing, Z., Graham, F.L., Csaky, K.G., and Gauldie, J. 1997. Adenovector-mediated gene transfer of active transforming growth factor-beta 1 induces prolonged severe fibrosis in rat lung. J. Clin. Invest. 100:768-776.
12. Wakefield, L., et al. 1990. Regulation of transforming growth factor-beta subtypes by members of the steroid hormone superfamily. J. Cell Sci. Suppl. 13:139-148.

13. Elovic, A.E., et al. 1998. IL-4-dependent regulation of TGF-alpha and TGF-beta1 expression in human eosinophils. J. Immunol. 160:6121-6127.

14. Ohkawara, Y., et al. 2000. Activation and transforming growth factor-beta production in eosinophils by hyaluronan. Am. J. Respir. Cell. Mol. Biol. 23:444-451.

15. Grewal, J.S., Mukhin, Y.V., Garnovskaya, M.N., Raymond, J.R., and Greene, E.L. 1999. Serotonin 5-HT2A receptor induces TGF-beta1 expression in mesangial cells via ERK: proliferative and fibrotic signals. Am. J. Physiol. 276:F922-F930.

16. Baumgartner, R.A., Deramo, V.A., and Beaven, M.A. 1996. Constitutive and inducible mechanisms for synthesis and release of cytokines in immune cell lines. J. Immunol. 157:4087-4093.

17. Khabar, K.S. 2005. The AU-rich transcriptome: more than interferons and cytokines, and its role in disease. J. Interferon Cytokine Res. 25:1-10.

18. Lopez de Silanes, I., Zhan, M., Lal, A., Yang, X., and Gorospe, M. 2004. Identification of a target RNA motif for RNA-binding protein HuR. Proc. Natl. Acad. Sci. U. S. A. 101:2987-2992.

19. Shen, Z.J., Esnault, S., and Malter, J.S. 2005. The peptidyl-prolyl isomerase Pin1 regulates the stability of granulocyte-macrophage colony-stimulating factor mRNA in activated eosinophils. Nat. Immunol. 6:1280-1287.

20. Esnault, S., Shen, Z.J., Whitesel, E., and Malter, J.S. 2006. The peptidyl-prolyl isomerase pin 1 regulates granulocyte-macrophage colony-stimulating factor mRNA stability in T lymphocytes. J. Immunol. 177:6999-7006.

21. Wulf, G., Finn, G., Suizu, F., and Lu, K.P. 2005. Phosphorylation-specific prolyl isomerization: is there an underlying theme? Nat. Cell Biol. 7:435-441.

22. Nabors, L.B., Gillespie, G.Y., Harkins, L., and King, P.H. 2001. HuR, a RNA stability factor, is expressed in malignant brain tumors and binds to adenineand uridine-rich elements within the 3 ' untrans- lated regions of cytokine and angiogenic factor mRNAs. Cancer Res. 61:2154-2161.

23. Czaplinski, K., et al. 2005. Identification of 40LoVe, a Xenopus hnRNP D family protein involved in localizing a TGF-beta-related mRNA during oogenesis. Dev. Cell. 8:505-515.

24. Hennig, L., et al. 1998. Selective inactivation of parvulin-like peptidyl-prolyl cis/trans isomerases by juglone. Biochemistry. 37:5953-5960.

25. Bates, M.E., et al. 2004. Expression of interleukin-5and granulocyte macrophage-colony-stimulating factor-responsive genes in blood and airway eosinophils. Am. J. Respir. Cell Mol. Biol. 30:736-743.

26. Esnault, S., and Malter, J.S. 2003. Hyaluronic acid or TNF-alpha plus fibronectin triggers granulocyte macrophage-colony-stimulating factor mRNA stabilization in eosinophils yet engages differential intracellular pathways and mRNA binding proteins. J. Immunol. 171:6780-6787.

27. Ignatovich, I.A., et al. 2003. Complexes of plasmid DNA with basic domain 47-57 of the HIV-1 Tat protein are transferred to mammalian cells by endocytosis-mediated pathways. J. Biol. Chem. 278:42625-42636.

28. Chao, S.H., Greenleaf, A.L., and Price, D.H. 2001. Juglone, an inhibitor of the peptidyl-prolyl isomerase Pin1, also directly blocks transcription. Nucleic Acids Res. 29:767-773.

29. Esnault, S., et al. 2007. A critical role for Pin 1 in allergic pulmonary eosinophilia in rats. J. Allergy Clin. Immunol. 120:1082-1088.

30. Martiny-Baron, G., et al. 1993. Selective inhibition of protein kinase $\mathrm{C}$ isozymes by the indolocarbazole Gö6976. J. Biol. Chem. 268:9194-9197.

31. Rose, A., et al. 2004. The luteinizing hormone-releasing hormone inhibits the anti-apoptotic activity of insulin-like growth factor- 1 in pituitary alphaT3 cells by protein kinase $\mathrm{C}$ alpha-mediated negative regulation of Akt. J. Biol. Chem. 279:52500-52516.

32. Liu, B., et al. 1995. 12(S)-hydroxyeicosatetraenoic acid and 13(S)-hydroxyoctadecadienoic acid regulation of protein kinase C-alpha in melanoma cells: role of receptor-mediated hydrolysis of inositol phospholipids. Proc. Natl. Acad. Sci. U. S. A. 
92:9323-9327.

33. Liu, B., Maher, R.J., Hannun, Y.A., Porter, A.T., and Honn, K.V. 1994. 12(S)-HETE enhancement of prostate tumor cell invasion: selective role of PKC alpha. J. Natl. Cancer Inst. 86:1145-1151.

34. Parekh, D.B., Ziegler, W., and Parker, P.J. 2000. Multiple pathways control protein kinase C phosphorylation. EMBO J. 19:496-503.

35. Bornancin, F., and Parker, P.J. 1996. Phosphorylation of threonine 638 critically controls the dephosphorylation and inactivation of protein kinase C alpha. Curr. Biol. 6:1114-1123.

36. Jensen, T.J., et al. 1995. Multiple proteolytic systems, including the proteasome, contribute to CFTR processing. Cell. 83:129-135.

37. Boudreau, R.T., Garduno, R., and Lin, T.J. 2002. Protein phosphatase $2 \mathrm{~A}$ and protein kinase $\mathrm{C}$ alpha are physically associated and are involved in Pseudomonas aeruginosa-induced interleukin 6 production by mast cells. J. Biol. Chem. 277:5322-5329.

38. Sarkar, B., Xi, Q., He, C., and Schneider, R.J. 2003. Selective degradation of AU-rich mRNAs promoted by the 37 AUF1 protein isoform. Mol. Cell. Biol. 23:6685-6693.

39. Piecyk, M., et al. 2000. TIA-1 is a translational silencer that selectively regulates the expression of TNF-alpha. EMBO J. 19:4154-4163.

40. Fan, X.C., and Steitz, J.A. 1998. Overexpression of HuR, a nuclear-cytoplasmic shuttling protein, increases the in vivo stability of ARE-containing mRNAs. EMBO J. 17:3448-3460.

41. Blaxall, B.C., Pende, A., Wu, S.C., and Port, J.D. 2002. Correlation between intrinsic mRNA stability and the affinity of AUF1 (hnRNP D) and HuR for A+U-rich mRNAs. Mol. Cell. Biochem. 232:1-11.

42. Lal, A., et al. 2004. Concurrent versus individual binding of HuR and AUF1 to common labile target mRNAs. EMBO J. 23:3092-3102.

43. Esnault, S., et al. 2007. Pin 1 modulates the type 1 immune response. PLOS ONE. 2:e226.

44. Schramm, C.M., et al. 2004. Chronic inhaled ovalbumin exposure induces antigen-dependent but not antigen-specific inhalational tolerance in a murine model of allergic airway disease. Am. J. Pathol. 164:295-304.

45. Subbaramaiah, K., et al. 2003. Regulation of cyclooxgenase- 2 mRNA stability by taxanes: evidence for involvement of p38, MAPKAPK-2, and HuR. J. Biol. Chem. 278:37637-37647.

46. Evans, D.J., et al. 1999. Expression and activation of protein kinase C-zeta in eosinophils after allergen challenge. Am. J. Physiol. 277:L233-L239.

47. Ricciarelli, R., and Azzi, A. 1998. Regulation of recombinant PKC alpha activity by protein phosphatase 1 and protein phosphatase 2A. Arch. Biochem. Biophys. 355:197-200.

48. Rao, R.K., and Clayton, L.W. 2002. Regulation of protein phosphatase $2 \mathrm{~A}$ by hydrogen peroxide and glutathionylation. Biochem. Biophys. Res. Commun. 293:610-616

49. Li, D., Wang, F., Lai, M., Chen, Y., and Zhang, J.F. 2005. A protein phosphatase $2 \mathrm{c}$ alpha-Ca2+ channel complex for dephosphorylation of neuronal $\mathrm{Ca} 2+$ channels phosphorylated by protein kinase $\mathrm{C}$. J. Neurosci. 25:1914-1923.

50. Gates, J., Jr., Ferguson, S.M., Blakely, R.D., and Apparsundaram, S. 2004. Regulation of choline transporter surface expression and phosphorylation by protein kinase $\mathrm{C}$ and protein phosphatase 1/2A. J. Pharmacol. Exp. Ther. 310:536-545.

51. Guo, H., and Damuni, Z. 1993. Autophosphorylation-activated protein kinase phosphorylates and inactivates protein phosphatase 2A. Proc. Natl. Acad. Sci. U. S. A. 90:2500-2504.

52. Chen, C.Y., et al. 2001. AU binding proteins recruit the exosome to degrade ARE-containing mRNAs. Cell. 107:451-464.

53. Hajarnis, S., Schroeder, J.M., and Curthoys, N.P. 2005. 3'-Untranslated region of phosphoenolpyruvate carboxykinase mRNA contains multiple instability elements that bind AUF1. J. Biol. Chem. 280:28272-28280.

54. Brightling, C.E., et al. 2003. Comparison of airway immunopathology of eosinophilic bronchitis and asthma. Thorax. 58:528-532.

55. Schneider, T., van Velzen, D., Moqbel, R., and Issekutz, A.C. 1997. Kinetics and quantitation of eosinophil and neutrophil recruitment to allergic lung inflammation in a brown Norway rat model. Am. J. Respir. Cell Mol. Biol. 17:702-712.

56. Sorkness, R.L., Remus, J.L., and Rosenthal, L.A. 2004. Systemic and pulmonary effects of fluticasone administered through a metered-dose inhaler in rats. J. Allergy Clin. Immunol. 114:1027-1032.

57. Hansel, T.T., et al. 1991. An improved immunomagnetic procedure for the isolation of highly purified human blood eosinophils. J. Immunol. Methods. 145:105-110.

58. Hirano, A., et al. 2006. Pirfenidone modulates airway responsiveness, inflammation, and remodeling after repeated challenge. Am. J. Respir. Cell Mol. Biol. 35:366-377.

59. Sorkness, R.L., Herricks, K.M., Szakaly, R.J., Lemanske, R.F., Jr., and Rosenthal, L.A. 2006. Altered allergen-induced eosinophil trafficking and physiologic dysfunction in airways with preexisting virus-induced injury. Am. J. Physiol. Lung Cell Mol. Physiol. 292:L85-L91. 